\title{
Analisis Halal Supply Chain pada Usaha Mikro Kecil Menengah (UMKM) Makanan di Kota Bandung
}

\author{
Fauzan Aziz $^{\text {), }}$, Retno Setyorini ${ }^{2)}$, Yulia Nur Hasanah ${ }^{3 *}$ \\ ${ }^{1,2,3}$ Fakultas Komunikasi dan Bisnis, Telkom University \\ *E-mail: yulianh@telkomuniversity.ac.id
}

Halal supply chain is a concept where halal is not only seen as raw materials and production processes, but also involves in supply chain process. Indonesia, as the country with the largest Muslim population in the world, only has 20\% of products that are halal certified, especially food Small Medium Enterprise (SMEs) in Bandung who most of which do not have halal certification. Therefore, this study aims to conduct a Halal Supply Chain Analysis of Small Medium Enterprise (SME) in Bandung. This research uses quantitative research methods with an associative descriptive approach. The sampling technique used simple random sampling with a total sample size of 94 food SMEs in Bandung. The data analysis technique used the Structural Equation Model-Partial Least Square (SEM-PLS) method. Based on the research results, the success factor of Halal Supply Chain has a positive and significant effect on the Implementation of Halal Supply Chain in Food SMEs in Bandung, with a contribution of $63.8 \%$ and the remaining $36.2 \%$ is explained by other factors not examined. This shows that the implementation of Halal Supply Chain will be successful if SMEs pay attention to each success factor of the Halal Supply Chain. This research This research can provide new insights for researchers regarding the halal supply chain in SMEs and can be used for future research. In addition, this research can also be used by practitioners to improve the SMEs halal supply chain management which will later increase the halal market.

Keywords: Halal, Supply Chain, SMEs, Food

Saran sitasi: Aziz, F., Setyorini, R., \& Hasanah, Y. N. (2021). Analisis Halal Supply Chain pada Usaha Mikro Kecil Menengah (UMKM) Makanan di Kota Bandung. Jurnal Ilmiah Ekonomi Islam, 7(01), 293-301. doi:http://dx.doi.org/10.29040/jiei.v7i1.1936

\section{DOI: http://dx.doi.org/10.29040/jiei.v7i1.1936}

\section{PENDAHULUAN}

Agama Islam merupakan agama yang secara dominan berada di wilayah Asia Tenggara, Timur Tengah, Afrika Utara dan beberapa bagian Asia lainnya. Jumlah pemeluk agama Islam di dunia juga akan bertambah dari 24 persen di tahun 2019 menjadi 26 persen di tahun 2030 (Pew Research Center, 2011). Indonesia sebagai negara dengan mayoritas penduduk muslim (Fleishman-Hillard Majlis, 2013) sudah seharusnya mempunyai kewajiban dalam menjamin kehalalan setiap produk yang dikonsumsi, agar terciptanya rasa aman di masyarakat dalam menjalankan setiap perintah agama. Salah satu upaya yang dilakukan pemerintah dalam menjamin kehalalan produk yaitu dengan menyediakan sertifikasi halal oleh Majelis Ulama Indonesia. Produk-produk Indonesia yang berupa barang yang dipakai, digunakan, atau dimanfaatkan oleh masyarakat wajib bersertifikasi halal, kecuali produk yang memang berasal dari bahan yang haram.

Di Indonesia, usaha mikro kecil menengah (UMKM) menjadi salah satu sektor dengan kontribusi terbesar terhadap Produk Domestik Bruto (PDB) yaitu mencapai 60 persen (Julaika, 2020) dan karena Indonesia memiliki kewajiban menjamin kehalalan produk, maka pelaku UMKM perlu melakukan penyesuaian dan persiapan terkait sertifikasi halal. Hal tersebut dilakukan agar pelaku UMKM mampu menjaga dan mempertahankan kehalalan produk mulai dari bahan mentah sampai pada konsumen akhir. UMKM di Kota Bandung terus mengalami peningkatan dari tahun 2012 dengan jumlah 3.291 UMKM menjadi 4.296 UMKM di tahun 2019 (Dinas Koperasi UMKM, 2019). Peningkatan jumlah UMKM tersebut dikarenakan adanya pendampingan dari pemerintah yang secara konsisten dilakukan. Pendampingan tersebut dilakukan sampai UMKM 


\section{Jurnal Ilmiah Ekonomi Islam, 7(01), 2021, 294}

mampu naik kelas atau meningkatkan kualitas produk. Khususnya untuk UMKM pada sektor makanan yang menjadi kategori unit usaha terbanyak (Dinas Koperasi UMKM, 2019). Hingga saat ini, masih sedikit pelaku UMKM di Kota Bandung yang memiliki sertifikasi halal dan masih sebatas pada kegiatan produksi, belum mencakup setiap rantai pasok.

Menurut Heizer \& Render (2015) manajemen rantai pasok menggambarkan koordinasi dari keseluruhan kegiatan rantai pasokan, dimulai dari bahan baku dan diakhiri dengan pelanggan yang puas. Dengan demikian, sebuah rantai pasok mencakup pemasok, perusahaan manufaktur dan/atau penyedia jasa, dan perusahaan distributor, grosir, dan/atau pengecer yang mengantarkan produk dan/jasa ke konsumen akhir. Rantai pasok terdiri dari semua pihak yang terlibat, baik secara langsung maupun tidak langsung, dalam memenuhi permintaan pelanggan. Rantai pasok tidak hanya mencakup pabrik dan pemasok, tetapi juga pengangkut, gudang, pengecer, dan bahkan pelanggan itu sendiri. Selanjutnya, manajemen rantai pasok halal merupakan proses pengelolaan pengadaan, pergerakan, penyimpanan dan penanganan bahan, persediaan, barang setengah jadi, makanan dan non-makanan yang sesuai dengan prinsip syariah (Bahrudin, Tan, \& Desa, 2011). Tieman (2011) menyebutkan bahwa dasar utama rantai pasok halal adalah informasi yang mengalir dalam setiap rantai pasok harus sesuai dengan prinsipprinsip hukum syariah.

Terdapat beberapa faktor yang menjadi kunci sukses rantai pasok halal (Ab Talib, Hamid, \& Zulfakar, 2015) yaitu dukungan pemerintah, asset khusus, teknologi informasi, sumber daya manusia, hubungan kolaborasi, sertifikasi halal, dan ketelusuran halal. Dukungan pemerintah dalam kesuksesan rantai pasok halal berupa dukungan untuk membantu dan mempromosikan industri halal, seperti mendirikan otoritas sertifikasi halal, menyediakan insentif untuk bisnis halal, mendanai penelitian tentang studi terkait halal melalui universitas dan lembaga penelitian, dan menyelenggarakan pelatihan halal untuk praktisi industri (Goh dan Pinaikul, 1998). Aset khusus sangat penting dalam rantai pasok halal dan pemisahan sepanjang rantai pasok akan meningkatkan integritas halal. Kunci dalam aset khusus adalah pemisahan antara produk halal dan non-halal selama distribusi, dan menyediakan asset berbeda dalam hal transportasi, pergudangan, atau peralatan (Ab Talib,
Hamid, \& Zulfakar, 2015). Teknologi informasi memiliki dampak signifikan pada logistik dan manajemen rantai pasok, dimana salah satu atribut kunci manajemen rantai pasok adalah mengambil keuntungan dan pengawasan melalui teknologi (Murphy \& Wood, 2004). Selanjutnya, teknologi informasi dapat mengintegrasikan teknologi untuk pertukaran informasi selama proses tracking dan tracing guna pengukuran kinerja operasi dan pengawasan (Santos Vieira, Sérgio, \& Luna, 2013). Sumber daya manusia juga menjadi kunci kesuksesan rantai pasok karena sumber daya manusia adalah nilai kolektif dari kemampuan, pengetahuan, keterampilan, pengalaman hidup, dan motivasi organisasi tenaga kerja (Yoon, Song, Lim, \& Joo, 2010) yang akan mempengaruhi rantai pasok halal. Selanjutnya, hubungan kolaborasi rantai pasok merupakan kepercayaan (visibilitas), mutualitas, pertukaran informasi, keterbukaan dan komunikasi (Näslund \& Hulthen, 2012) yang dibutuhkan dalam kelancaran rantai pasok halal. Faktor berikutnya adalah sertifikasi halal yang menjadi bukti bahwa produk memenuhi prosedur pembuatan halal, memberikan jaminan kepada konsumen sebagai produk yang aman untuk dikonsumsi umat muslim (Nakyinsige, Man, \& Sazili, 2012). Faktor terakhir adalah ketelusuran halal yang dapat menciptakan nilai kompetitif dengan mengintegrasikan sistem keterlacakan dengan proses manajemen rantai pasok dan menggunakan data keterlacakan untuk mengelola dan meningkatkan proses bisnis (Bevilacqua, Ciarapica, \& Giacchetta, 2009). Faktor-faktor tersebut merupakan faktor yang mendukung dalam proses penerapan rantai pasok halal, tetapi dari faktor-faktor tersebut yang menjadi kunci utama penerapan rantai pasok halal adalah adanya sertifikasi halal diseluruh kegiatan rantai pasok (Tieman, 2011).

Tujuan dari penelitian ini adalah untuk menganalisis bagaimana rantai pasok halal (halal supply chain) pada pelaku UMKM makanan di Kota Bandung berdasarkan faktor keberhasilan rantai pasok halal dan penerapan rantai pasok halal. Penelitian ini menjelaskan pengaruh faktor keberhasilan rantai pasok halal pada UMKM makanan di kota Bandung terhadap penerapan rantai pasok halal.

\section{METODE PENELITIAN}

Penelitian ini menggunakan metode penelitian kuantitatif dengan metode deskriptif asosisatif. Penelitian kuantitatif merupakan penelitian yang 
berlandaskan pada filsafat positivisme yang digunakan untuk meneliti pada populasi atau sampel tertentu, pengumpula data menggunakan instrumen penelitian, analisis data bersifat kuantitatif atau statistik, dengan tujuan untuk menguji hipotesis yang telah ditetapkan (Sugiyono, 2018). Selanjutnya penelitian ini menggunakan metode deskriptif asosisatif yang bertujuan untuk mendapatkan data yang menggambarkan topik yang menarik mulai dari karakteristik objek, peristiwa, atau situasi dengan mengetahui hubungan antar variable (Sekaran \& Bougie, 2016). Sehingga dapat disimpulkan metode ini bertujuan untuk mengetahui karakteristik dari masing-masing variable serta hubunga antara faktor keberhasilan rantai pasok halal dengan penerapan rantai pasok halal.

Penelitian ini dilakukan pada Usaha Mikro Kecil Menengah (UMKM) Kota Bandung dengan total populasi 1.533 UMKM (Dinas Koperasi dan UMKM Kota Bandung). Penelitian ini menggunakan rumus Slovin (Sugiyono, 2017) untuk menentukan sample dan didapatkan 94 sampel UMKM yang digunakan dalam penelitian ini. Teknik pengumpulan data yang dilakukan dalam penelitian ini adalah menggunakan kuesioner dengan variabel bebas yaitu faktor keberhasilan rantai pasok halal (X) dan variabel terikat yaitu penerapan rantai pasok halal (Y). Kuesioner ini menggunakan skala ordinal dan skala Likert untuk memeriksa seberapa kuat subjek setuju atau tidak terhadap pernyataan menggunakan skala satu sampai lima.

Data yang telah dikumpulkan kemudian diuji menggunakan uji validitas untuk menguji seberapa baik instrument yang dikembangkan dalam mengukur dan uji reliabilitas untuk menguji keandalan suatu pengukuran. Selanjutnya analisis data dilakukan dengan menggunakan analisis deskriptif untuk mengetahui karakteristi dari setiap variabel yang diteliti. Penelitian ini melakukan analisis deskriptif untuk mengetahui karakteristik dari setiap variabel yang diteliti dengan menyusun kriteria penilaian untuk setiap pertanyaan dalam kuesioner berdasarkan presentase. Selanjutnya, penelitian ini mengubah hasil kuesioner yang berskala ordinal menjadi interval menggunakan Method of Successive Interval (MSI) untuk melakukan perhitungan statistik. Uji hipotesis dilakukan menggunakan Partial Least Square (PLS) yang terbagi ke dalam analisisi outer model dan analisis inner model. Analisis outer model menggambarkan hubungan antara setiap indikator dengan variabel latennya menggunakan convergent validity, discriminant validity, composite reliability, average variance extracted (AVE) dan Cronbach Alpha. Sedangkan analisis inner model dilakukan untuk megetahui probabilitas menggunakan $p$-value dan t-statistik.

\section{HASIL DAN PEMBAHASAN}

\subsection{Hasil Penelitian}

Dalam pengambilan data, peneliti menggunakan kuesioner yang disebar kepada pelaku UMKM makanan yang tersebar di Kota Bandung secara online. Adapun hasil yang diperoleh dari penyebaran kuesioner ini terdapat 111 responden dan terdapat 17 responden dinyatakan tidak valid karena tidak memenuhi kriteria yaitu unit usaha yang dijalankan bukan berasal dari Kota Bandung. Sehingga hasil data kuesioner yang digunakan sebanyak 94 responden.

\subsubsection{Analisis Deskriptif}

Analisis ini dilakukan untuk melihat karakteristik setiap variable bebas $(\mathrm{X})$ dan variable terikat $(\mathrm{Y})$. Berdasarkan hasil perhitungan analisis deskriptif yaitu dengan menghitung skor total, skor ideal, dan kategori persentase skor setiap indikator yang digunakan untuk menggambarkan setiap variable menunjukan bahwa variabel terikat $(\mathrm{Y})$ yaitu penerapan rantai pasok halal memiliki presentase skor sebesar 92 persen yang berada dalam kategori sangat baik (Tabel 1) dan variabel terikat $(\mathrm{X})$ yaitu faktor keberhasilan rantai pasok halal memiliki presentase skor sebesar 89 persen yang juga berada dalam kategori sangat baik (Tabel 2).

Tabel 1. Persentase Skor per Indikator Variabel X

\begin{tabular}{|c|c|c|c|c|}
\hline No & Indikator & $\sum$ Skor & $\begin{array}{c}\% \\
\text { Skor }\end{array}$ & $\begin{array}{l}\text { Skor } \\
\text { Ideal }\end{array}$ \\
\hline 1 & $\begin{array}{l}\text { Proses produksi } \\
\text { memenuhi prosedur halal }\end{array}$ & 439 & $93 \%$ & 470 \\
\hline 2 & $\begin{array}{l}\text { Bahan yang digunakan } \\
\text { halal }\end{array}$ & 446 & $95 \%$ & 470 \\
\hline 3 & $\begin{array}{l}\text { Adanya pemisahan } \\
\text { transportasi antara produk } \\
\text { halal dan non halal }\end{array}$ & 411 & $87 \%$ & 470 \\
\hline 4 & $\begin{array}{l}\text { Adanya pemisahan } \\
\text { penyimpanan antara } \\
\text { produk halal dan non halal }\end{array}$ & 428 & $91 \%$ & 470 \\
\hline 5 & $\begin{array}{l}\text { Adanya pemisahan produk } \\
\text { halal dan non halal dalam } \\
\text { proses pergerakan produk }\end{array}$ & 431 & $92 \%$ & 470 \\
\hline & Jumlah & 2155 & $92 \%$ & 2350 \\
\hline
\end{tabular}


Jurnal Ilmiah Ekonomi Islam, 7(01), 2021, 296

Tabel 2. Persentase Skor per Indikator Variabel X

\begin{tabular}{|c|c|c|c|c|}
\hline No & Indikator & $\sum$ Skor & \begin{tabular}{|c|}
$\%$ \\
Skor
\end{tabular} & $\begin{array}{l}\text { Skor } \\
\text { Ideal }\end{array}$ \\
\hline 1 & $\begin{array}{l}\text { Adanya pemisahan produk } \\
\text { halal dan non halal di } \\
\text { bandara yang disediakan } \\
\text { pemerintah }\end{array}$ & 416 & $89 \%$ & 470 \\
\hline 2 & $\begin{array}{l}\text { Adanya pemisahan produk } \\
\text { halal dan non halal di } \\
\text { pelabuhan yang } \\
\text { disediakan pemerintah }\end{array}$ & 415 & $88 \%$ & 470 \\
\hline 3 & $\begin{array}{l}\text { Adanya lembaga } \\
\text { sertifikasi halal yang } \\
\text { disediakan pemerintah }\end{array}$ & 435 & $93 \%$ & 470 \\
\hline 4 & $\begin{array}{l}\text { Perusahaan tidak } \\
\text { mencampur produk halal } \\
\text { dengan non - halal dalam } \\
\text { sistem transportasi }\end{array}$ & 426 & $91 \%$ & 470 \\
\hline 5 & $\begin{array}{l}\text { Perusahaan tidak } \\
\text { mencampur produk halal } \\
\text { dengan non - halal dalam } \\
\text { penyimpanan produk di } \\
\text { gudang }\end{array}$ & 432 & $92 \%$ & 470 \\
\hline 6 & $\begin{array}{l}\text { Peralatan yang digunakan } \\
\text { perusahaan tidak } \\
\text { digunakan untuk produk } \\
\text { non - halal }\end{array}$ & 423 & $90 \%$ & 470 \\
\hline 7 & $\begin{array}{l}\text { Teknologi informasi } \\
\text { memudahkan pengukuran } \\
\text { kinerja operasi }\end{array}$ & 418 & $89 \%$ & 470 \\
\hline 8 & $\begin{array}{l}\text { Perusahaan melakukan } \\
\text { pelatihan penerapan halal } \\
\text { supply chain }\end{array}$ & 414 & $88 \%$ & 470 \\
\hline 9 & $\begin{array}{l}\text { Seluruh karyawan mampu } \\
\text { dalam penerapan halal } \\
\text { supply chain }\end{array}$ & 409 & $87 \%$ & 470 \\
\hline 10 & $\begin{array}{l}\text { Seluruh karyawan } \\
\text { memiliki pengetahuan } \\
\text { mengenai penerapan halal } \\
\text { supply chain }\end{array}$ & 407 & $87 \%$ & 470 \\
\hline 11 & $\begin{array}{l}\text { Seluruh karyawan } \\
\text { terampil dalam penerapan } \\
\text { halal supply chain }\end{array}$ & 400 & $85 \%$ & 470 \\
\hline 12 & $\begin{array}{l}\text { Seluruh karyawan } \\
\text { berpengalaman dalam } \\
\text { penerapan halal supply } \\
\text { chain }\end{array}$ & 389 & $83 \%$ & 470 \\
\hline 13 & $\begin{array}{l}\text { Perusahaan memberikan } \\
\text { motivasi kepada karyawan }\end{array}$ & 433 & $92 \%$ & 470 \\
\hline 14 & $\begin{array}{l}\text { Adanya keprecayaan } \\
\text { dalam setiap rantai pasok }\end{array}$ & 416 & $89 \%$ & 470 \\
\hline
\end{tabular}

\begin{tabular}{|c|l|c|c|c|}
\hline No & \multicolumn{1}{|c|}{ Indikator } & $\Sigma$ Skor & $\begin{array}{c}\text { \% } \\
\text { Skor }\end{array}$ & $\begin{array}{c}\text { Skor } \\
\text { Ideal }\end{array}$ \\
\hline 15 & $\begin{array}{l}\text { Adanya pertukaran } \\
\text { informasi diantara rantai } \\
\text { pasok }\end{array}$ & 407 & $87 \%$ & 470 \\
\hline 16 & $\begin{array}{l}\text { Produk memenuhi } \\
\text { prosedur halal }\end{array}$ & 423 & $90 \%$ & 470 \\
\hline 17 & $\begin{array}{l}\text { Adanya jaminan } \\
\text { keamanan produk }\end{array}$ & 429 & $91 \%$ & 470 \\
\hline 18 & $\begin{array}{l}\text { Keterlacakan informasi } \\
\text { meningkatkan proses } \\
\text { bisnis }\end{array}$ & 423 & $90 \%$ & 470 \\
\hline \multicolumn{2}{|c|}{ Jumlah } & 7515 & $89 \%$ & 8460 \\
\hline
\end{tabular}

\subsubsection{Analisis Outer Model}

\section{a. Convergent Validity}

Menurut Hussein (2015:18) convergent validity adalah nilai loading faktor pada variabel laten dengan indikator-indikatornya. Nilai yang diharapkan > 0,7. Selanjutnya, menurut Hair et al., (2014:111), Rule of Thumb yang baik adalah skor loading faktor harus 0,5 atau lebih tinggi dan idealnya 0,7 atau lebih tinggi. Berikut adalah nilai loading faktor untuk masingmasing indikator variabel penelitian berdasarkan hasil ouput SmartPLS:

Tabel 3. Hasil Convergent Validity

\begin{tabular}{|c|c|c||}
\hline Variabel & Indikator & Loading Faktor \\
\hline \multirow{4}{*}{$\begin{array}{c}\text { Faktor } \\
\text { Keberhasilan }\end{array}$} & $\mathrm{X} 1$ & 0,595 \\
\cline { 2 - 3 } Rantai Pasok & $\mathrm{X} 2$ & 0,632 \\
\cline { 2 - 3 } Halal (X) & $\mathrm{X} 3$ & 0,659 \\
\cline { 2 - 3 } & $\mathrm{X} 5$ & 0,680 \\
\cline { 2 - 3 } & $\mathrm{X} 6$ & 0,587 \\
\cline { 2 - 3 } & $\mathrm{X} 7$ & 0,556 \\
\cline { 2 - 3 } & $\mathrm{X} 8$ & 0,670 \\
\cline { 2 - 3 } & $\mathrm{X} 10$ & 0,754 \\
\cline { 2 - 3 } & $\mathrm{X} 11$ & 0,815 \\
\cline { 2 - 3 } & $\mathrm{X} 12$ & 0,799 \\
\cline { 2 - 3 } & $\mathrm{X} 13$ & 0,819 \\
\cline { 2 - 3 } & $\mathrm{X} 14$ & 0,816 \\
\cline { 2 - 3 } & $\mathrm{X} 15$ & 0,698 \\
\cline { 2 - 3 } & $\mathrm{X} 16$ & 0,762 \\
\cline { 2 - 3 } & $\mathrm{X} 17$ & 0,676 \\
\cline { 2 - 3 } & $\mathrm{X} 18$ & 0,750 \\
\hline \multirow{4}{*}{$\begin{array}{c}\text { Penerapan } \\
\text { Hantai Pasok }\end{array}$} & $\mathrm{Y} 1$ & 0,729 \\
\cline { 2 - 3 } & $\mathrm{Y} 2$ & 0,688 \\
\cline { 2 - 3 } & $\mathrm{Y} 3$ & 0,741 \\
\cline { 2 - 3 } & $\mathrm{Y} 4$ & 0,747 \\
\cline { 2 - 3 } & $\mathrm{Y} 5$ & 0,849 \\
\hline
\end{tabular}


Berdasarkan Tabel 3 diatas dapat disimpulkan bahwa nilai loading faktor unuk masing-masing indikator $>0,5$ atau dengan kata lain tidak ada nilai loading faktor yang dibawah nilai 0,5 , hal ini menunjukan bahwa semua indikator dinyatakan valid untuk digunakan dalam penelitian.

\section{b. Discriminant Validity}

Discriminant validity adalah nilai cross loading faktor yang berguna untuk mengetahui apakah konstruk memiliki diskriminan yang memadai yaitu dengan cara membandingkan nilai loading pada konstruk yang dituju harus lebih besar dibandingkan dengan nilai loading dengan konstruk yang lain. Berikut adalah nilai cross loading faktor untuk masingmasing indikator variabel penelitian berdasarkan hasil ouput SmartPLS:

Tabel 4. Hasil Discriminant Validity

\begin{tabular}{|c|c|c|}
\hline & FK $(X)$ & $\operatorname{HSC}(Y)$ \\
\hline $\mathrm{X1}$ & 0,595 & 0,413 \\
\hline $\mathrm{X} 2$ & 0,632 & 0,428 \\
\hline X3 & 0,659 & 0,511 \\
\hline X4 & 0,680 & 0,477 \\
\hline X5 & 0,587 & 0,392 \\
\hline X6 & 0,556 & 0,470 \\
\hline $\mathrm{X} 7$ & 0,670 & 0,513 \\
\hline $\mathrm{X8}$ & 0,754 & 0,583 \\
\hline X9 & 0,815 & 0,620 \\
\hline $\mathbf{X 1 0}$ & 0,799 & 0,517 \\
\hline X11 & 0,819 & 0,553 \\
\hline $\mathrm{X12}$ & 0,816 & 0,635 \\
\hline $\mathbf{X 1 3}$ & 0,698 & 0,643 \\
\hline $\mathrm{X14}$ & 0,762 & 0,641 \\
\hline $\mathrm{X15}$ & 0,676 & 0,475 \\
\hline $\mathrm{X16}$ & 0,750 & 0,680 \\
\hline $\mathbf{X 1 7}$ & 0,729 & 0,730 \\
\hline $\mathrm{X18}$ & 0,688 & 0,670 \\
\hline Y1 & 0,573 & 0,741 \\
\hline Y2 & 0,669 & 0,747 \\
\hline Y3 & 0,656 & 0,849 \\
\hline Y4 & 0,641 & 0,804 \\
\hline Y5 & 0,672 & 0,881 \\
\hline
\end{tabular}

Berdasarkan Tabel 4 diatas nilai cross loading untuk setiap indikator pada konstruk yang dituju memiliki nilai lebih besar dari pada nilai cross loading untuk setiap indikator pada konstruk lain. Hal ini menunjukan bahwa konstruk pada penelitian memiliki diskriminan yang memadai.

\section{c. Composite Reliability}

Composite Reliabilitas digunakan untuk menguji nilai reliabilitas masing-masing indikator pada suatu variabel. Suatu variabel dapat dinyatakan reliabel bila memiliki nilai composite reliability $>0,7$. Berikut adalah nilai composite reliability untuk masingmasing variabel penelitian berdasarkan hasil ouput SmartPLS:

Tabel 5. Composite Reliability

\begin{tabular}{|c|c|}
\hline & Composite Reliability \\
\hline FK $(\mathbf{X})$ & 0,947 \\
\hline HSC(Y) & 0,903 \\
\hline
\end{tabular}

Berdasarkan Tabel 5 diatas nilai composite reliability untuk masing-masing variabel > 0,7 , dimana nilai composite reliability untuk faktor keberhasilan halal supply chain (X) sebesar 0,947 dan nilai composite reliability untuk penerapan halal supply chain (Y) sebesar 0,903. Hal ini menunjukan bahwa variabel dalam penelitian ini memiliki tingkat reliabilitas tinggi.

\section{d. Cronbach Alpha}

Menurut Hussein (2015:18) uji reliabilitas diperkuat dengan Cronbach Alpha. Nilai diharapkan $>0,6$ untuk semua konstruk. Berikut ini adalah nilai Cronbach Alpha untuk masing-masing variabel penelitian berdasarkan hasil output SmartPLS:

Tabel 6. Cronbach Alpha

\begin{tabular}{|c|c|}
\hline & Cronbach Alpha \\
\hline FK (X) & 0,941 \\
\hline HSC(Y) & 0,864 \\
\hline
\end{tabular}

Berdasarkan Tabel 6 diatas nilai Cronbach Alpha pada masing-masing variabel penelitian $>0,6$, dimana faktor keberhasilan halal supply chain (X) memiliki nilai cronbach alpha sebesar 0,941 dan penerapan halal supply chain (Y) memiliki nilai cronbach alpha sebesar 0,864. Berdasarkan hal tersebut dapat diambil kesimpulan bahwa masing-masing variabel dalam penelitian ini memiliki tingkat reliabilitas tinggi atau reliabel.

\subsubsection{Analisis Inner Model}

\section{a. Koefisien determinan $\left(\mathbf{R}^{2}\right)$}

Koefisien determinan (R2) digunakan untuk mengukur tingkat variasi perubahan variabel independen terhadap variabel dependen. Nilai $R^{2}$ yang dijelaskan pada variabel dependen sebaiknya $\geq 0,10$ (Abdillah \& Hartono, 2015 : 185). Berikut adalah nilai koefisien determinan $\left(\mathrm{R}^{2}\right)$ berdasarkan hasil output SmartPLS: 
Tabel 7. Koefisien Determinan $\left(\mathrm{R}^{2}\right)$

\begin{tabular}{|c|c|}
\hline & R Square $\left(\mathbf{R}^{2}\right)$ \\
\hline HSC (Y) & 0,638 \\
\hline
\end{tabular}

Berdasarkan Tabel 7 diatas nilai R Square (R2) untuk variabel penerapan halal supply chain (Y) adalah sebesar 0,638 atau 63,8\%. Hal ini menunjukan bahwa penerapan halal supply chain (Y) dapat dijelaskan oleh faktor keberhasilan halal supply chain (X) sebesar $63,8 \%$ dan sisanya sebesar 36,2\% dijelaskan oleh faktor lain yang tidak diteliti.

\section{b. Cross-validated Redundancy (Q2) tau Q- square test}

Q-square test digunakan untuk menilai predictive relevance. Predictive relevance untuk model struktur mengukur seberapa baik nilai observasi yang dihasilkan oleh model dan juga estimasi parameternya. Nilai $\mathrm{Q}^{2}>0$ menunjukan bahwa model mempunyai predictive relevance yang akurat terhadap konstruk tertentu sedangkan nilai $\mathrm{Q}^{2}<0$ menunjukan bahwa model kurang mempunyai predictive relevance (Hair et al., 2017). Berikut adalah nilai Q-square $\left(\mathrm{Q}^{2}\right)$ berdasarkan hasil perhitungan SmartPLS:

Tabel 8. Cross-validated Redundancy $\left(\mathrm{Q}^{2}\right)$

\begin{tabular}{|c|c|c|c|}
\hline & SSO & SSE & $\begin{array}{c}\mathbf{Q}^{2} \leq(=1- \\
\text { SSE/SSO })\end{array}$ \\
\hline FK (X) & $1.692,000$ & $1.692,000$ & \\
\hline HSC (Y) & 470,000 & 281,509 & 0,401 \\
\hline
\end{tabular}

Berdasarkan Tabel 8 nilai Q-square $>0$ atau sebesar 0,401 hal ini menunjukan bahwa model struktur mempunyai predictive relevance yang akurat yaitu adanya relevansi atau kesesuaian antara variabel dependen yang dipengaruhi oleh variabel independen atau dengan kata lain variabel independen relevan untuk memprediksi variabel dependen.

\section{c. Goodness of Fit (GoF)}

Goodness of Fit $(G o F)$ merupakan pengukuran kelayakan suatu model. Nilai GoF tidak diperoleh dari hasil output SmartPLS namun harus dihitung secara manual. GoF adalah rata-rata geometri dari rata-rata communality dan rata-rata R-square. Artinya GoF sama dengan akar kuadrat dari communality dikali Rsquare. GoF akan bervariasi antara 0 sampai 1 (Garson, 2016). Adapun rumus GoF dapat dilihat pada persamaan 1.

$$
\text { GoF }=\sqrt{\text { com } \times R-\text { square }}
$$

Keterangan:

Com : adalah rata rata dari nilai communality yang dapat diketahui dari pengukuran model dengan teknik blindfloding pada bagian construct validated communality.

R-square : adalah nilai R-square yang dapat diketahui dari pengukuran model dengan teknik PLS Algorithm pada bagian R-square.

Tabel 9. Nilai rata-rata communality

\begin{tabular}{|c|c|c|}
\hline & Communality & Rata-rata Com \\
\hline FK (X) & 0,429 & \\
\hline HSC (Y) & 0,468 & 0,4485 \\
\hline
\end{tabular}

Berdasarkan Tabel 9 nilai rata-rata communality adalah sebesar 0,4485. Sedangkan nilai R-square dapat dilihat pada Tabel 7 yaitu sebesar 0,638. Dengan demikian nilai GoF yang diperoleh adalah 0,54 yang menunjukan bahwa model memiliki tingkat kecocokan atau kelayakan yang baik.

\subsubsection{Uji Hipotesis}

Dalam pengujian hipotesis ada beberapa kriteria yang harus dipenuhi, yaitu original sample, t-statistic dan p-value. Dimana nilai pada original sample untuk mengetahui hubungan antar variabel independen dan variabel dependen.

Tingkat signifikansi $(\alpha)$ digunakan untuk menunjukan probabilitas atau peluang kesalahan yang ditetapkan peneliti dalam mengmbil keputusan untuk menolak atau menerima hipotesis nol. Pada penelitian ini, peneliti menggunakan tingkat signifikansi sebesar $10 \%$ atau 0,10 , artinya tingkat kepercayaan penelitian ini sebesar $90 \%$, dengan derajat kebebasan $(d f)$ sebesar $92(n-k=92, n=94, k=2, n$ adalah jumlah sampel dan $\mathrm{k}$ adalah banyaknya variabel penelitian). Berdasarkan hal tersebut maka dapat diketahui bahwa t-tabel dalam penelitian ini adalah sebesar 1,662 (dapat dilihat pada daftar t-tabel df (92) dan $\alpha(10 \%)$ ), artinya bila t-statistic bernilai lebih dari atau sama dengan 1,662 (t-statistic $\geq 1,662$ ), maka pengaruh yang diberikan oleh variabel independen terhadap variabel dependen yaitu signifikan.

Selain itu signifikansi suatu penelitian juga dapat diuji menggunakan p-value. Adapun p-value yang harus terpenuhi dalam penelitian ini adalah $<0,10$. Dengan demikian bila 3 komponen tersebut yaitu original sample, t-statistic dan p-value terpenuhi, maka hipotesis penelitian dapat diterima. Namun bila salah satu kriteria tersebut tidak terpenuhi, maka secara otomatis hipotesis penelitian tertolak. Berikut adalah hasil uji hipotesisi berdasarkan hasil output SmartPLS: 
Jurnal Ilmiah Ekonomi Islam, 7(01), 2021, 299

Tabel 10. Uji Hipotesis

\begin{tabular}{|c|c|c|c|c|c|}
\hline & $\begin{array}{c}\text { Original Sample } \\
\text { Sampel } \\
(\mathbf{O})\end{array}$ & $\begin{array}{c}\text { Mean } \\
(\mathbf{M})\end{array}$ & $\begin{array}{c}\text { Standar } \\
\text { Erorr } \\
\text { (STRER } \\
\text { R) }\end{array}$ & $\begin{array}{c}\text { T } \\
\text { Statistic } \\
(|\mathbf{O}| \text { STR } \\
\text { ERR })\end{array}$ & $\begin{array}{c}\text { P } \\
\text { Values }\end{array}$ \\
\hline $\begin{array}{c}\text { FK (X) }- \\
>\text { HSC } \\
(\mathbf{Y})\end{array}$ & 0,799 & 0,804 & 0,043 & 18,371 & 0,000 \\
\hline
\end{tabular}

Berdasarkan Tabel 10 diatas nilai original sample bernilai positif sebesar 0,799 yang menujukan bahwa variabel faktor keberhasilan halal supply chain (X) terhadap penerapan halal supply chain (Y) memiliki arah hubungan yang positif. Selain itu nilai t-statistic bernilai 18,371 yaitu lebih besar dari t-tabel $(18,371 \geq$ $1,662)$ dan p-value bernilai 0,000 yaitu kurang dari $0,10(0,000<0,10)$, hal ini menunjukan pengaruh yang diberikan variabel faktor keberhasilan halal supply chain (X) terhadap penerapan halal supply chain (Y) adalah signifikan. Dengan demikian hipotesis yang menyatakan faktor keberhasilan halal supply chain (X) terhadap penerapan halal supply chain (Y) dapat diterima.

\subsection{Pembahasan}

Penelitian ini dilakukan untuk mengetahui pengaruh Faktor Keberhasilan Halal Supply Chain (X) terhadap Penerapan Halal Supply Chain (Y) pada Pelaku Usaha Mikro Kecil Menengah (UMKM) Makanan di Kota Bandung. Berdasarkan hasil penelitian ini, teknik analisis data yang digunakan dalam penelitian ini menggunakan analisis deskriptif dan pengujian PLS yang terdiri dari analisis outer model, analisis inner model dan analisis hipotesis.

Analisis deskriptif dalam penelitian ini memperoleh kategori sangat baik berdasarkan garis kontinum. Dimana Faktor Keberhasilan Halal Supply Chain (X) memperoleh skor rata-rata sebesar $89 \%$ dengan jumlah item pernyataan sebanyak 18 butir instrumen, artinya para pelaku UMKM Makanan di Kota Bandung menyatakan bahwa keberhasilan halal supply chain perlu memperhatikan beberapa faktor berikut, yaitu adanya dukungan pemerintah, aset khusus, teknologi informasi, sumberdaya manusia, hubungan kolaboratif, sertifikasi halal, dan ketelusuran halal. Sementara Penerapan Halal Supply Chain (Y) memperoleh skor rata-rata $92 \%$ dengan jumlah item pernyataan sebanyak 5 butir instrumen, artinya pelaku UMKM Makanan di Kota bandung telah mampu melakukan penerapan halal supply chain ini dengan baik, dimana kegiatan produksi, bahan yang digunakan, kegiatan transportasi, proses penyimpanan, dan proses handling telah sesuai dengan konsep halal.

Analisis outer model meliputi convergent validity, discriminant validity, composite reliability dan cronbach alpha. Dimana hasil convergent validity untuk setiap indikator penelitian dinyatakan valid, karena nilai setiap indikator diatas 0,5 . Selanjutnya discriminant validity menunjukan bahwa konstruk memiliki diskriminan yang memadai, karena nilai cross loading untuk setiap indikator pada konstruk yang dituju memiliki nilai lebih tinggi dari pada konstruk lain. Hasil composite reliability dan cronbach alpha menunjukan variabel Faktor Keberhasilan Halal Supply Chain (X) dan Penerapan Halal Supply Chain (Y) memiliki reliabilitas yang tinggi, dimana nilai dari composite reliability untuk masing-masing variabel secara berturut-turut memiliki nilai sebesar 0,947 dan 0,903 yaitu $>0,7$ sebagai syarat diterimanya composite reliability dan nilai dari cronbach alpha untuk masing-masing variabel secara berturut-turut memiliki nilai sebesar 0,941 dan 0,864 yaitu $>0,6$ sebagai syarat diterimanya cronbach alpha.

Analisis inner model meliputi koefisen determinan (R2), cross-validated redudancy dan goodness of fit (GoF). Dimana hasil R2 menunjukan bahwa penerapan halal supply chain (Y) dapat dijelaskan oleh faktor keberhasilan halal supply chain (X) sebesar $63,8 \%$ dan sisanya sebesar 36,2\% dijelaskan oleh faktor lain yang tidak diteliti. Selanjutnya cross-validated redudancy mempunyai nilai Q-square > 0 atau sebesar 0,401 hal ini menunjukan bahwa model struktur mempunyai predictive relevance yang akurat. Dan yang terakhi adalah goodness of fit $(\mathrm{GoF})$ memiliki nilai sebesar 0,54 , hal ini menunjukan bahwa model memiliki tinggkat kecocokan atau kelayakan yang baik.

Berdasarkan hasil analisis hipotesis yang telah dilakukan menunjukan bahwa semua kriteria, yaitu original sample, $t$-statistic dan $p$-value dapat terpenuhi, hal ini menunjukan bahwa hipotesis penelitian diterima dan terdapat pengaruh signifikan anatara Faktor Keberhasilan Halal Supply Chain (X) terhadap Penerapan Halal Supply Chain (Y) dengan arah yang positif. Hal ini menunjukan bahwa suksesnya Penerapan Halal Supply Chain bila pelaku usaha memperhatikan setiap Faktor Keberhasilan Halal Supply Chain itu sendiri, dimana hal ini didukung oleh penelitian Talib et al. (2015) yang menyatakan bahwa terdapat beberapa faktor kunci/ 


\section{Jurnal Ilmiah Ekonomi Islam, 7(01), 2021, 300}

faktor keberhasilan yang cocok dalam upaya penerapan halal secara global dengan metode kualitatif dan literatur review.

\section{KESIMPULAN}

Penelitian ini bertujuan untuk mengetahui seberapa besar faktor keberhasilan, penerapan, dan seberapa besar pengaruh halal supply chain di pelaku UMKM Makanan di kota Bandung. Penelitian ini menggunakan metode penelitian kuantitatif yang melibatkan 94 UMKM Makanan di kota Bandung sebagai objek penelitian. Berdasarkan hasil penelitian didapatkan bahwa variabel Faktor Keberhasilan Halal Supply Chain (X) secara keseluruhan memiliki skor rata-rata sebesar $89 \%$ yaitu masuk dalam kategori sangat baik berdasarkan garis kontinum. Dari 18 butir instrumen pada item pernyataan " Adanya lembaga sertifikasi halal yang disediakan pemerintah" memiliki skor tertinggi yaitu sebesar $93 \%$ dan skor terendahnya adalah sebesar $83 \%$ pada item pernyataan "Seluruh karyawan berpengalaman dalam penerapan halal supply chain". Selanjutnya, variabel Penerapan Halal Supply Chain (Y) secara keseluruhan memiliki skro rata-rata sebesar $92 \%$ yaitu masuk kategori sangat baik berdasarkan garis kontinum. Dari 5 butir instrumen pada item pernyataan "Bahan yang digunakan halal" memiliki skro tertinggi yaitu sebesar 95\% dan skro terendahnya adalah sebesar $87 \%$ pada item pernyataan "Adanya pemisahan transportasi antara produk halal dan non halal". Sedangkan, faktor Keberhasilan Halal Supply Chain (X) berpengaruh positif dan signifikan terhadap Penerapan Halal Supply Chain (Y) pada Pelaku Usaha Mikro Kecil Menengah (UMKM) Makanan di Kota Bandung, dengan kontribusi sebesar $63,8 \%$ dan sisanya sebesar $36,2 \%$ dipengaruhi oleh faktor lain yang tidak diteliti dalam penelitian ini.

\section{UCAPAN TERIMA KASIH}

Dalam menyelesaikan penelitian ini, kami ingin menyampaikan rasa terima kasih kepada berbagai pihak atas bantuan, bimbingan, petunjuk dan saransaran, serta nasehat yang tidak ternilai harganya. Ucapan terima kasih kami sampaikan kepada Allah SWT, atas rahmat dan karunianya penelitian ini dapat terselesaikan. Rektor Telkom University atas dukungan seluruh program strategis di lingkungan Telkom University. Wakil Rektor Bidang Riset, Inovasi, dan Kerjasama atas dukungan program pengembangan penelitian dan inovasi di lingkungan
Telkom University. Direktur Penelitian dan Pengabdian Kepada Masyarakat atas dukungan program penelitian bagi dosen di lingkungan Telkom University. Dekan Fakultas Komunikasi dan Bisnis atas kerjasama, bimbingan dan arahan dalam penelitian ini. UMKM di Kota Bandung atas partisipasi yang diberikan dalam mendukung penelitian ini. Tim Peneliti atas waktu, energi dan seluruh dukungan yang diberikan untuk menyelesaikan penelitian ini. Penelitian sebelumnya dan semua peneliti yang berkontribusi pada penelitian ini

\section{REFERENSI}

Ab Talib, M., Hamid, A., \& Zulfakar, M. (2015). Halal Supply Chain Critical Success Factors: A Literature Review. Journal of Islamic Marketing, Vol.6, 44 - 71. [10.1108/JIMA-07-2013-0049].

Bahrudin, S., Tan, M., \& Desa, M. (2011). Tracking and tracing technology for halal product integrity over the supply chain. Proceedings of the 2011 International Conference on Electrical Engineering and Informatics, ICEEI 2011. 1-7. [10.1109/ICEEI.2011.6021678].

Bevilacqua, M., Ciarapica, F. E., \& Giacchetta, G. (2009). Business process reengineering of a supply chain and a traceability system: A case study. Journal of Food Engineering, 93(1), 1322. doi:10.1016/j.jfoodeng.2008.12.020

Dinas Koperasi UMKM Kota Bandung (2019). Pertumbuhan UMKM di Kota Bandung. http://diskopumkm.bandung.go.id/page/home

Flieshman-Hillard Majlis (2013). The Market Opportunity of the Muslim Word. http://fleishmanhillard.com/wp-

content/uploads/meta/resource-file/2013/majliswhite-paper-1367425353.pdf

Goh, M., \& Pinaikul, P. (1998). Logistics management practices and development in Thailand. Logistics Information Management.

Heizer, J. \& Render, B. (2015). Manajemen Operasi. Jakarta: Salemba Empat

Julaika, H. (31 Agustus 2020). Kontribusi ke PDB hingga $60 \%$ UMKM Terus Digenjot URL https://mediaindonesia.com/nusantara/340785/k ontribusi-ke-pdb-hingga-60-umkm-terusdigenjot

Murphy, P. R. \& Wood, D. F. (2004). Contemporary Logistics 8th International Edition. Pearson Prentice Hall, Singapore. 
Nakyinsige, K., Man, Y. B. C., \& Sazili, A. Q. (2012). Halal authenticity issues in meat and meat products. Meat science, Vol.91, No.3 : 207-214.

Näslund, D., \& Hulthen, H. (2012). Supply chain management integration: a critical analysis. Benchmarking: An International Journal.

Pew Research Center (2011). The Future of The Global Muslim Population. https://www.pewforum.org/2011/01/27/thefuture-of-the-global-muslim-population/

Santos Vieira, C., Sérgio, A., \& Luna, M.M. (2013). ICT implementation process model for logistics service providers. Industrial Management \& Data Systems, Vol.113, No.4 : 484-505.

Sekaran, U., \& Bougie, R. (2016). Research methods for business: A skill building approach. John Wiley \& Sons.
Sugiyono. (2017). Metode Penelitian Bisnis (ed. Ke13). Bandung : Alfabeta

Sugiyono. (2018). Metode Penelitian : Kuantitatif, Kualitatif, dan R\&D. Bandung : Alfabeta, CV

Tieman, Marco. (2011). The application of Halal in supply chain management: In-depth interviews. Journal of Islamic Marketing, Vol.2, 186-195. [10.1108/17590831111139893].

Yoon, S. W., Song, J. H., Lim, D. H., \& Joo, B.K. (2010). Structural determinants of team performance: the mutual influences of learning culture, creativity, and knowledge. Human Resource Development International, Vol.13, No.3 249-264. [10.1080/13678868.2010.483815]. 